\title{
Spinosad: a biorational mosquito larvicide for use in car tires in southern Mexico
}

\author{
Carlos F Marina' ${ }^{1}$ J Guillermo Bond ${ }^{1}$, José Muñoz ${ }^{1}$, Javier Valle² ${ }^{2}$ Nelva Chirino ${ }^{1}$ and Trevor Williams ${ }^{3 *}$
}

\begin{abstract}
Background: Car tires are important habitats for mosquito development because of the high density populations they can harbor and their presence in urban settings. Water in experimental tires was treated with one of three insecticides or an untreated control. Aquatic invertebrates were sampled at weekly intervals. Eggs, larval and pupal samples were laboratory-reared to estimate seasonal fluctuations in Aedes aegypti and Ae. albopictus abundance.

Results: Spinosad treatments at 1 or 5 ppm (mg a.i./liter) provided 6-8 weeks of effective control of Ae. aegypti, Ae. albopictus, Culex quinquefasiatus and Cx. coronator larvae, both in the dry season and the rainy season when mosquito populations increased markedly in southern Mexico. Spinosad continued to provide partial control of larvae for several weeks after initial recolonization of treated tires. The larvicidal performance of VectoBac 12AS (Bacillus thuringiensis var. israelensis) was relatively poor with one week of complete control of Aedes spp. larvae and no discernible control of Culex spp., whereas the duration of larvicidal activity of $1 \%$ temephos mineral-based granules was intermediate between those of VectoBac and spinosad treatments. Populations of chironomids, ostracods and Toxorhynchites theobaldi were generally reduced in spinosad and temephos treatments, but were similar in control and VectoBac treatments.
\end{abstract}

Conclusion: The present study is the first to report spinosad as an effective larvicide against $C x$. coronator, which is currently invading the southern United States. These results substantiate the use of spinosad as a highly effective mosquito larvicide, even in habitats such as unused car tires that can represent prolific sources of adult mosquitoes.

\section{Background}

Used car tires are an important habitat for the development of container-dwelling mosquitoes many of which are important vectors of human and wildlife arboviruses. International trade in tires that may contain mosquito immature stages has become an important mechanism for the human-assisted dispersal of some exotic species [1], most notably Ae. albopictus that has reached the Americas, Africa and Europe via contaminated car tires $[2,3]$. Tire storage facilities, recycling plants and discarded tires are therefore likely to represent localized sources of medically-important mosquito species in rural and urban settings. The public health importance of mosquito development in tires is clearly recognized [4]. Tires provide four characteristics that favor the development of container-dwelling mosquitoes: (i) they provide

\footnotetext{
* Correspondence: trevor.inecol@gmail.com

${ }^{3}$ Instituto de Ecología AC, Xalapa, Veracruz, Mexico

Full list of author information is available at the end of the article
}

shaded conditions in their interior that is favored for oviposition by many species, (ii) their dark color promotes rapid warming in sunlight that speeds larval development. This can advance the seasonal occurrence of vector species in some regions [5], (iii) their shape tends to collect rainfall, seeds and leaf detritus efficiently providing food resources for developing larvae [6,7], and (iv) tires can remain undisturbed for long periods allowing sequential generations to reach extremely high population densities at some sites [8]. Moreover, the vector potential of certain species depends on the conditions they experience during development. In this respect, mosquitoes that develop in tires may be smaller and more susceptible to infection by viruses from vertebrate hosts than conspecifics that develop in natural habitats [9].

The prevalence of vector borne viruses in the human population is a major public health issue in Mexico and many other parts of Latin America and elsewhere [10-12]. The economic impact of dengue virus alone has been conservatively estimated at US $\$ 2.1$ billion per year

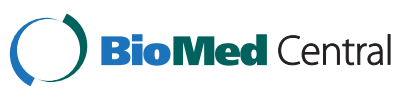


in the Americas, mainly in lost productivity and direct medical attention [13].

In Mexico, the principal vector, Aedes aegypti, is sympatric over much of its range with the invasive Asian tiger mosquito, Ae. albopictus that is currently invading the country from both northern and southern borders $[14,15]$. Ae albopictus has been firmly implicated as a vector of dengue and several other mortal arboviruses [16]. As such, the latter species represents a major emerging public health threat in the Americas $[17,18]$. Other mosquito species of medical importance in this region include Culex species, particularly $C x$. quinquefasiatus and $C x$. coronator. Both these species have the capacity to disseminate various arboviruses including West Nile virus, an emerging pathogen in the Americas [19].

Vector control programs currently focus on the elimination of larval development habitats, often in combination with the treatment of water sources with larvicides, the success of which requires considerable community participation [20]. These measures are accompanied by intra-domiciliary residual spraying, streetlevel fogging or aerial application of insecticides during outbreaks of vector borne disease [21].

The principal larvicide used for control of Ae. aegypti populations in developing countries is the organophosphate temephos (Abate), that is often applied to potential larval habitats as a mineral granule formulation. The widespread use of this compound has led to the development of resistance in some regions [22,23]. In countries with greater resources available for public health programs, temephos has now been replaced with biological insecticides based on Bacillus thuringiensis var. israelensis or other biorational agents that are derived from, or mimic, natural substances.

Spinosad is a biorational insecticide produced during the fermentation of an actinomycete. Spinosad is mixture of two spinosyn neurotoxins that are highly toxic to certain orders of insects, including Diptera. However, spinosad has very little toxicity to vertebrates and has recently been approved for use as a mosquito larvicide in human drinking water [24].

Spinosad has been shown to be effective in preventing or reducing the development of immature aquatic stages of important vector species, particularly Ae. aegypti and Ae. albopictus, Anopheles gambiae, An. pseudopunctipennis, An. albimanus, $C x$. pipiens and $C x$. quinquefasicatus, among others [25]. Most of these studies have been performed under laboratory conditions; studies on the control of these species in natural habitats are limited in number.

The aim of the present study was to evaluate the efficacy of spinosad as a larvicide in car tire habitats. For this, the performance of spinosad as a larvicide was compared with a Bti-based product, VectoBac, and temephos granules in experimental car tires in an urban environment in southern Mexico.

\section{Methods}

Insecticides

Spinosad was obtained as a liquid suspension concentrate formulation (Tracer 480SC, Dow Agrosciences LLC, Indianapolis, IN) containing $480 \mathrm{~g}$ active ingredient (a.i.)/l. Bti was obtained as a suspension concentrate (VectoBac 12AS, Valent BioSciences Corp., Libertyville, IL) containing 12,000 international toxicity units (ITU)/ml. Temephos was obtained as a generic mineral granular formulation comprising $1 \%$ a.i. (wt./wt.) provided by the Secretaria de Salud (Mexican government).

\section{Field trials in used car tires}

These experiments were performed in a tire repair yard $\left(14^{\circ} 50^{\prime} \mathrm{N} ; 92^{\circ} 11^{\prime} \mathrm{W}\right)$ surrounded by housing in an urbanized zone in the town of Metapa, Chiapas at an altitude of $100 \mathrm{~m}$ above sea level. A total of 75 used car tires were arranged in five rows with 15 tires per row, all in an unshaded location. The distance between tires was $4 \mathrm{~m}$ with $7 \mathrm{~m}$ distance between adjacent rows, covering a total area of $36 \times 60 \mathrm{~m}$. Each tire was perforated to create a $5 \mathrm{~cm}$ hole in the wall of the tire. Each tire was tied using a nylon rope that was fixed to a wooden stake $1.2 \mathrm{~m}$ in height that ensured that every tire remained upright during the experiment. A 4-liter volume of dechlorinated tap water was poured into each tire at the start of the experiment.

A strip of filter paper $(2 \mathrm{~cm}$ width $\times 15 \mathrm{~cm}$ length, Whatman No. 2) attached to a wooden spatula was placed resting against the inner side of each tire as an oviposition substrate.

Pre-treatment sampling was performed at weekly intervals. This involved 3 weekly samples taken in the experiment performed during the dry season and 2 weekly samples taken in the experiment performed during the rainy season. In both cases, the sample taken one day prior to the application of experimental treatments was considered as timepoint zero. Prior to each sample, tire water temperature was measured using glass laboratory thermometers (range -30 to $50^{\circ} \mathrm{C}$ ). Ambient air temperature and humidity at the experimental site were measured using a digital thermometer-hygrometer (Sper Scientific, Scottsdale, AZ). All temperature and humidity measurements were performed between 09:00 and 12:00 hrs.

Sampling involved emptying the liquid in each tire through the $5 \mathrm{~cm}$ hole in the tire wall. The liquid was poured through a fine nylon mesh net $(20 \mathrm{~cm}$ diameter and with a pore size of $0.70 \times 0.17 \mathrm{~mm}$ ) into a small bucket. Aquatic insects trapped in the net were immediately placed in a white plastic tray containing water, 
counted, visually identified to genus, recorded, placed in plastic tubes containing water, labeled and taken to the laboratory in an insulated box. The water from the bucket was examined for the presence of additional arthropods and replaced in the upright tire. Water that had evaporated during the intersample period was replaced with dechlorinated tap water to achieve a total volume of 4 liters. The filter paper oviposition substrate was removed and replaced with a new strip. Filter paper strips with evidence of oviposition were labeled and taken to the laboratory.

One day after the timepoint zero pre-treatment sample had been taken, one of five treatments was applied to 15 tires arranged in a randomized design. The treatments were (i) $1 \mathrm{mg}$ i.a/l spinosad ( $1 \mathrm{ppm}$ ), (ii) $5 \mathrm{mg}$ i.a/l spinosad (5 ppm), (iii) $0.4 \mathrm{~g} 1 \%$ temephos granules, (iv) $50 \mu \mathrm{l}$ Vectobac AS12; v) untreated water (control). Following the application of each treatment, tires were sampled at weekly intervals for a period of 12 weeks.

The first experiment commenced on 7 March 2007 during the dry season and ended on 13 June 2007 at the beginning of the rainy season. The second experiment started on 25 July and finished on 24 October 2007 that was completely within the period of the rainy season. Appropriate measures were taken to avoid cross-contamination between treatments.

\section{Laboratory rearing of larvae and eggs collected from tires.}

Larvae and pupae collected from tire samples, mainly third and fourth instars, were reared in groups (maximum 10 insects/group) in the CRISP (Centro Regional de Investigación en Salud Pública) insectary at $28 \pm 2^{\circ} \mathrm{C}$ in Tapachula, Chiapas, Mexico, and fed ad libitum on powdered diet (Laboratory Rodent Diet 5001, PMI Nutrition International, Saint Paul, MN). Adults that developed from these samples were identified to species.

Similarly, paper oviposition strips from tires were individually placed in plastic trays containing dechlorinated tap water in the CRISP insectary. Larvae that emerged from these eggs were reared on powdered diet, allowed to pupate and emerged as adults that were subsequently counted and identified to species. The proportion of hatched eggs was noted for each paper strip.

\section{Statistical analyses}

Numbers of Aedes spp. larvae and pupae were summed prior to analysis due to the low numbers of immature insects in some treatments. The same procedure was applied to larvae and pupae of Culex spp. and chironomids in separate analyses. Separate mixed models were then fitted using the results from each genus of insects. For this, a compound symmetry covariance structure was specified in SAS (SAS Institute Inc., Cary, NC). To define critical levels of significance Bonferroni correction was applied to all multiple comparison procedures that resulted in $\alpha=0.005$. To meet normality assumptions, numbers of eggs oviposited on paper strips required $\log _{\mathrm{e}}$ $(x+0.5)$ transformation whereas proportions of hatched eggs were arcsine-transformed $(\arcsin \sqrt{ } p)$ prior to analysis of variance with treatment and season (wet $v s$. dry) defined as factors. Numbers of ostracods and Toxorhynchites theobaldi immature stages were normalized by $\log _{e}(y+0.5)$ transformation and subjected to multivariate ANOVA (MANOVA). The significance of treatment differences was determined by Tukey test $(\mathrm{P}<0.05)$.

\section{Results}

\section{Dry season study}

The average $( \pm \mathrm{SE})$ air temperature during the dry season sampling period was $34.9 \pm 0.3^{\circ} \mathrm{C}$ (range $26.8-43.7^{\circ} \mathrm{C}$ ) whereas relative humidity averaged $55.3 \pm 1.1 \%$ (range 35 - $81 \%$ ). Average tire water temperature was $27.8 \pm 0.6^{\circ} \mathrm{C}$ (range $24-32^{\circ} \mathrm{C}$ ). The average volume of water that evaporated between sampling times was $0.92 \pm 0.03 \mathrm{~L}$; losses due to evaporation were replaced with dechlorinated water at each sample.

A total of 2,150 Aedes spp. larvae + pupae were observed in the three pre-treatment samples compared to 25,417 in the post-treatment samples. In total, 16,548 Culex spp. larvae + pupae were observed in pretreatment sampling compared to 22,284 in posttreatment samples. Very low numbers of Uranotaenia spp. $(\mathrm{N}=132)$ and Limatus spp. $(\mathrm{N}=6)$ were observed in post-treatment samples but not in pre-treatment samples; these minority species were not considered further. Chironomids were also present in samples: 165 individuals were observed in pre-treatment samples and 11,277 individuals in post-treatment samples. All chironomids appeared to be species of the genus Chironomus based on the characteristic red coloration of the larvae.

Larvae and pupae of Aedes spp. were present in all pre-treatment samples and increased in number during the pre-treatment sampling period in all cases (Figure 1A; statistical comparisons between treatments at each sample time shown in Figures 1,2 and 3 are given in Additional file 1 online: http://www.parasitesandvectors.com). Numbers of Aedes spp. in the control treatment fluctuated between 11.4 and 106.3 larvae + pupae/tire in each sample during the 12-week post-treatment period. One week post-treatment the numbers of Aedes spp. larvae + pupae was reduced to zero in all treatments except the control $\left(\mathrm{F}_{4,70}=30.2\right.$, $P<0.0001)$.

VectoBac treatment resulted in one week of control, after which numbers of Aedes spp. immature stages were similar to that of the control treatment until the end of 


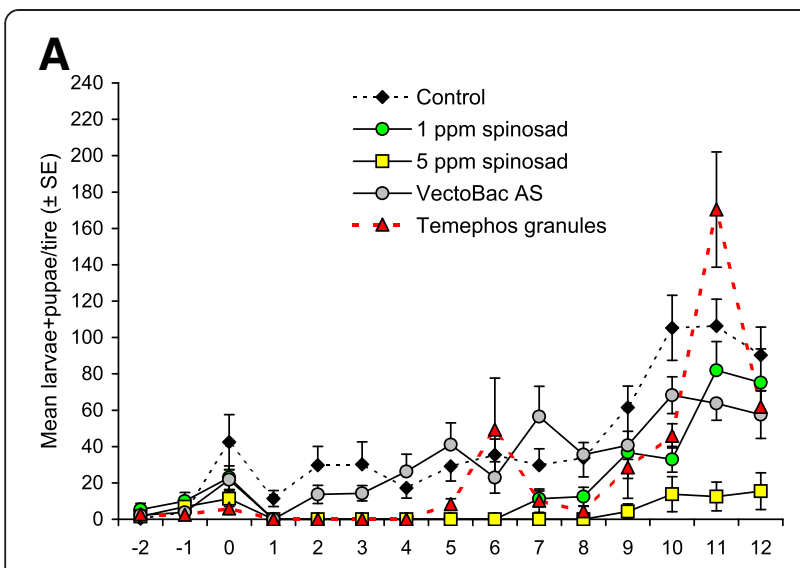

\section{B}

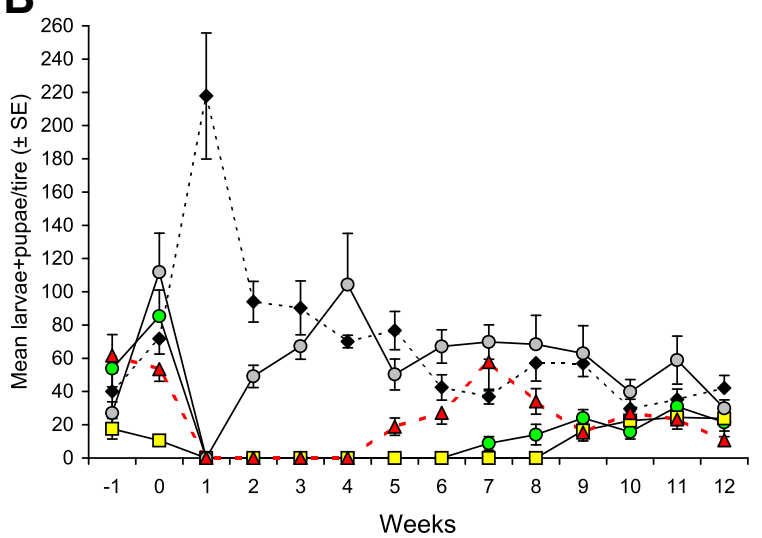

Figure 1 Mean $( \pm S E)$ numbers of Aedes spp. larvae + pupae observed in car tires sampled at weekly intervals pre- and post-treatment with insecticides in experiments performed in (A) dry season and (B) wet season, in southern Mexico.

For clarity, only half the error bar is shown for some points.

the trial. The $5 \mathrm{ppm}$ spinosad treatment was significantly more effective at controlling Aedes spp. immature stages than any of the other insecticide treatments $\left(\mathrm{F}_{14,979}=65.2, P<0.0001\right)$. Spinosad at concentrations of $1 \mathrm{ppm}$ or $5 \mathrm{ppm}$ provided 6 or 8 weeks of complete control, respectively, after which numbers of Aedes spp. were significantly lower than that of the control treatment until 9 or 12 weeks post-treatment, respectively (Figure 1A). Temephos granule treatment resulted in 4 weeks of complete control after which numbers of Aedes spp. fluctuated for 5 weeks before consistently reaching numbers similar to that of the control treatment at 10 weeks post-treatment.

Results on the control of Culex spp. larvae + pupae during the dry season were similar to those observed for Aedes spp. Pre-treatment observations revealed that Culex spp. immature stages were present in all treatments and were generally more abundant than Aedes spp. immature stages (Figure 2A). Numbers of Culex spp. in the control treatment varied between 25 and 110 larvae + pupae per tire during the post-treatment period. VectoBac treatment resulted in a significant but minor reduction in the numbers of Culex spp. at 1-week posttreatment, after which numbers remained significantly below control numbers in all samples taken thereafter, except for those samples taken at 2, 8, and 10 weeks post-treatment. The spinosad treatments provided longer lasting control of Culex immature stages than VectoBac or temephos treatments. The $1 \mathrm{ppm}$ spinosad treatment provided 6 weeks of absolute control followed by 6 weeks of partial control of Culex spp. whereas the 5 ppm spinosad treatment resulted in 8 weeks of complete control followed by 4 weeks of partial control with very low numbers of Culex larvae + pupae observed in tires from this treatment. In contrast, the temephos granule treatment resulted in 3 weeks of absolute control after which numbers fluctuated and were often similar to those observed in the control and VectoBac treatments (Figure 2A).

Colonization of tires by chironomids (mostly Chironomus spp.) was slow at the start of the dry season
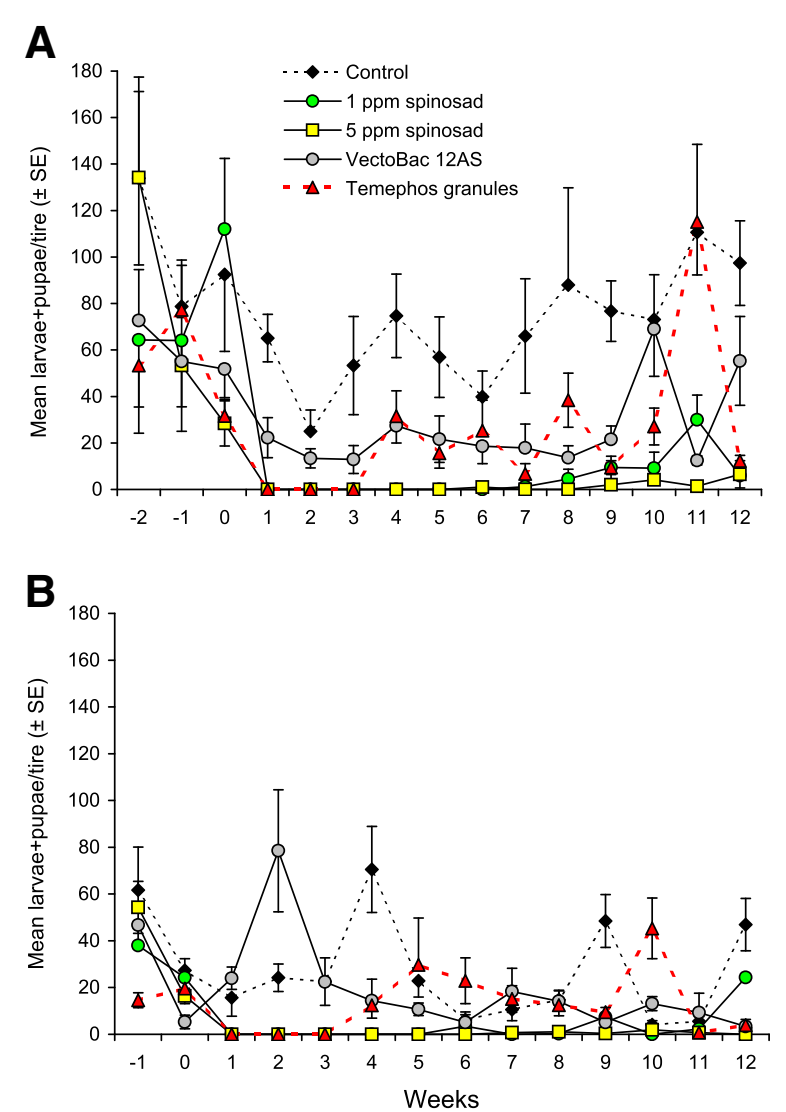

Figure 2 Mean $( \pm S E)$ numbers of Culex spp. larvae + pupae observed in car tires sampled at weekly intervals pre- and post-treatment with insecticides in experiments performed in (A) dry season and (B) wet season, in southern Mexico. For clarity, only half the error bar is shown for some points. 


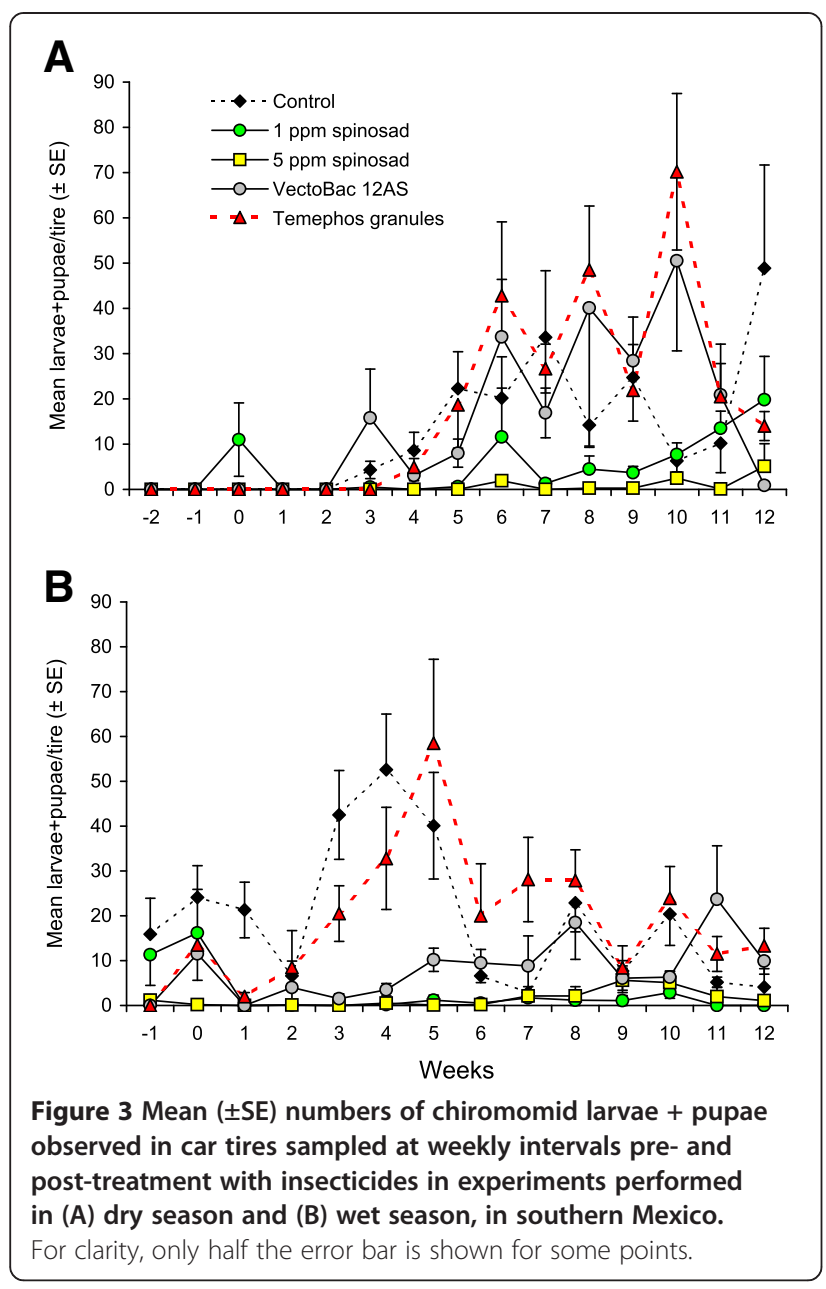

experiment. Larvae were only observed in one treatment during the pre-sampling period (Figure 3A). Similarly, chironomids did not colonize the control treatment until 3 weeks post-treatment. VectoBac provided no control of chironomid larvae whereas temephos granules delayed colonization for 1 week compared to the control treatment. In contrast, 1 ppm spinosad treatment resulted in reduced chironomid densities during weeks 4-9 of the dry season experiment compared to control densities. The most effective treatment was $5 \mathrm{ppm}$ spinosad that provided complete protection against chironomid colonization of tires for 5 weeks post-treatment and resulted in very low levels of chironomid larvae + pupae for the remaining 7 weeks of the experiment.

\section{Rainy season study}

The mean air temperature during the rainy season sampling period was $31.2 \pm 0.2^{\circ} \mathrm{C}$ (range $27-37^{\circ} \mathrm{C}$ ). Relative humidity varied from $57.7-86.8 \%$ with a mean value of $68.4 \pm 0.8 \%$. The average tire water temperature was $26.2 \pm 0.04^{\circ} \mathrm{C}$ (range $23-32^{\circ} \mathrm{C}$ ). The average volume of water that evaporated from tires between samples was
$0.80 \pm 0.02 \mathrm{~L}$; evaporational losses were replaced with dechlorinated water at each sample.

A total of 7,999 Aedes spp. larvae + pupae were observed during the pre-treatment period compared to 28,064 in the post-treatment samples. In total, 4,620 Culex spp. larvae + pupae were observed in pre-treatment sampling compared to 10,579 in post-treatment samples. Very low numbers of Uranotaenia spp. (7 specimens in pre-treatment samples and 66 in post-treatment samples) and Limatus spp. (79 specimens exclusively in posttreatment samples) were observed and were not considered further. A total of 1,408 chironimids were observed in pre-treatment samples and 9,270 in post-treatment samples. Almost all chironomids were members of the genus Chironomus, but were not identified to species.

Immature stages of Aedes spp. were registered in all treatments during pre-treatment sampling although significant differences were observed in pre-treatment samples that may be related to variation in the establishment of mosquito populations in the tires (Figure 1B). The numbers of Aedes larvae + pupae fluctuated between 29.7 and 217.8 individuals/tire during posttreatment sampling in the control treatment. Application of VectoBac provided 1 week of complete control of Aedes spp; samples taken subsequently indicated that this treatment did not provide significant control of Aedes immature stages during the period of the trial.

The $5 \mathrm{ppm}$ spinosad treatment was significantly more effective at controlling Aedes immature stages than any of the other treatments $\left(\mathrm{F}_{13,913}=48.1, P<0.0001\right)$. The $1 \mathrm{ppm}$ and $5 \mathrm{ppm}$ spinosad treatments resulted in complete control of Aedes spp. during 6 and 8 weeks, respectively. This was followed by a period of significantly reduced immature numbers in four of the five subsequent samples in the $1 \mathrm{ppm}$ spinosad treatment and in all four weekly samples taken during the final month of the trial in the $5 \mathrm{ppm}$ spinosad treatment (Figure 1B). Temephos treatment gave complete control of Aedes spp. for 4 weeks followed by partial but significant reductions in numbers of immature stages, compared to those registered in the control treatment, in six of the following eight samples.

In the case of Culex spp., immature stages were present in all treatments prior to the application of experimental treatments (Figure 2B). Numbers of Culex spp. larvae + pupae varied between 4.1 and 70.5 individuals/tire during post-treatment sampling in the control treatment. The VectoBac treatment had no immediate significant effect on numbers of Culex spp immature stages, although numbers in 4 out of 12 samples during the post-treatment period were significantly reduced compared to the control treatment.

The $1 \mathrm{ppm}$ spinosad treatment resulted in complete elimination of Culex immature stages for 5 weeks posttreatment, after which numbers of larvae + pupae 
remained very low or were absent until the 12-week sample (Figure 2B). Similarly, the $5 \mathrm{ppm}$ spinosad treatment resulted in a complete absence of Culex immature stages for 6 weeks post-treatment followed by very low numbers or absence of members of this genus until the end of the trial. The temephos treatment resulted in 3 weeks of absence of Culex spp. in tires. After that time numbers in the temephos treatment were statistically similar or higher than those observed in the control for 5 out of 9 samples, or for 8 out of 9 samples compared with the VectoBac treatment.

Tires were rapidly colonized by chironomids in the wet season experiment; chironomids were observed in all treatments in the zero timepoint sample, immediately prior to the application of each treatment (Figure 3B). Numbers of chironomid larvae + pupae in the control fluctuated between 2.9 and 52.6 during the posttreatment period. VectoBac and temephos granules provided 1 week of control of chironomids and thereafter numbers fluctuated in these treatments but did not differ significantly from those of the control in 6 of the following 11 samples. Both spinosad treatments resulted in significantly reduced chironomid numbers for the 12 week post-treatment period of the experiment, except for one sample in the $5 \mathrm{ppm}$ spinosad treatment taken at 10 weeks post-treatment (Figure 3B).

\section{Oviposition, egg hatch and laboratory rearing of field collected insects}

In the dry season, a total of 7451 eggs of Aedes spp. were registered on oviposition traps. Total egg numbers per treatment ranged from 1095 to 1916 (pooled across all samples) but did not differ significantly between treatments $\left(\mathrm{F}_{4,}, 70=1.9, \quad P=0.1\right)$. Of the eggs reared to adulthood in the laboratory, $53.8 \%(\mathrm{~N}=663)$ were Ae. albopictus and the remainder Ae. aegypti.

Significantly higher numbers of eggs were laid in the wet season compared to the dry season $\left(\mathrm{F}_{1,144}=5.7\right.$, $P=0.01$ ) with a total of 9581 Aedes spp. eggs registered on oviposition traps. Egg numbers on oviposition traps varied from $75.9 \pm 10.9$ eggs per replicate in the temephos treatment (total 1139) that was significantly reduced compared to the $5 \mathrm{ppm}$ spinosad treatment $(96.8 \pm 18.0)$, $1 \mathrm{ppm}$ spinosad $(157.3 \pm 26.5)$ VectoBac $(182.9 \pm 30.6)$ and control $(125.9 \pm 21.8)$ treatments $\left(F_{4,}, 70=3.3\right.$, $P=0.01)$.

Aedes albopictus was more prevalent in the wet season than in the dry season with $67.9 \%(\mathrm{~N}=1513)$ of the eggs reared to adulthood in the laboratory, being Ae. albopictus and the remainder Ae. aegypti. The percentage of egg hatch across all treatments increased significantly from $27.0 \%(\mathrm{~N}=75)$ in the dry season to $32.6 \%(\mathrm{~N}=75)$ in the rainy season $\left(F_{1}, 144=23.4, P<0.001\right)$. Percentage of egg hatch did not differ significantly between treatments in the dry season $\left(F_{4}, 70=0.5, P=0.7\right)$, whereas in the rainy season egg hatch was significantly higher in the temephos (36.8\%), control (33.4\%), VectoBac $(32.8 \%)$ and the 1 ppm spinosad (30.9\%) treatments compared to the $5 \mathrm{ppm}$ spinosad treatment (29.2\%) $\left(\mathrm{F}_{4,70}=3.2, P=0.018\right)$.

A total of 1681 adult mosquitoes were reared in the insectary from larvae and pupae collected from experimental tires during the dry season, $95.2 \%$ of which were identified to species. Of the Aedes spp. reared from larvae and pupae collected in the dry season, $52.8 \%$ $(\mathrm{N}=887)$ were Ae. aegytpti and $37.7 \%(\mathrm{~N}=634)$ were Ae. albopictus. The adult sex ratio was 0.45 male for Ae. albopictus and 0.48 male for Ae. aegypti. The remaining specimens comprised Culex coronator $0.24 \%$ $(\mathrm{N}=4)$, Haemagogus equinus $4.5 \%(\mathrm{~N}=76)$ and 80 specimens of Culex spp. (4.8\%) that were not identified to species. These species were clearly underrepresented in laboratory rearing that was designed specifically to estimate variation in the relative abundance of each of the Aedes species present.

Overall, $97.5 \%$ of adult mosquitoes reared in the laboratory from samples taken in the wet season were identified to species. Of the Aedes spp. reared from fieldcollected larvae and pupae, 64.3\% were Ae. albopictus $(\mathrm{N}=2533)$ and the remainder were Ae. aegypti $(\mathrm{N}=1098)$, and four specimens of Ae. podographicus. The adult sex ratio was 0.49 male in Ae. albopictus and 0.51 male in Ae. aegypti. Of the four remaining species that were not Aedes spp., $1.6 \%$ were $C x$. coronator $(\mathrm{N}=65), 0.3 \%$ were $C x$. quinquefasciatus $(\mathrm{N}=11), 2.5 \%$ Culex spp. $(\mathrm{N}=98)$, and the remainder $2.6 \%$ were Hg. equinus $(\mathrm{N}=104)$ or $0.6 \%$ Limatus durhamii $(\mathrm{N}=25)$, although again, these values are clearly underestimates of the prevalence of these species in tires.

\section{Effects on non-target organisms}

During the dry season experiment a total of 912 nontarget organisms were observed during post-treatment sampling. The most abundant predators of mosquito and chironomids were ostracods and the predatory mosquito Toxorhynchites theobaldi with 36 and 685 specimens, respectively, registered over the dry season study. Small numbers of coleopterans $(\mathrm{N}=10)$, copepods $(\mathrm{N}=6)$ were also registered, as were other organisms $(\mathrm{N}=275)$, most of which were insects that had likely drowned. Numbers of predatory ostracods and Tx. theobaldi differed significantly between treatments (Pillai's $\left.\mathrm{F}_{8}, 88=2.501, P=0.01\right)$. Predator Tx. theobaldi were absent in the 5 ppm spinosad and temephos treatments, whereas ostracod numbers were lowest in the two spinosad treatments during the dry season experiment (Table 1). 
Table 1 Mean $( \pm$ SE) numbers of Toxorhynchites theobaldi and ostracods observed in tires following insecticide treatments in the dry and wet season trials

\begin{tabular}{|c|c|c|c|c|}
\hline \multirow[t]{2}{*}{ Treatment } & \multicolumn{2}{|c|}{ Dry season } & \multicolumn{2}{|c|}{ Wet season } \\
\hline & $\begin{array}{l}T x . \\
\text { theobaldi }\end{array}$ & Ostracods & $\begin{array}{l}\text { Tx. } \\
\text { theobaldi }\end{array}$ & Ostracods \\
\hline Control & $1.3 \pm 1.1^{a}$ & $23.8 \pm 11.9^{a}$ & $6.8 \pm 2.3^{a}$ & $9.7 \pm 5.1^{a}$ \\
\hline VectoBac 12AS & $0.4 \pm 0.4^{\mathrm{ab}}$ & $24.5 \pm 12.6^{a}$ & $2.2 \pm 1.3^{\mathrm{ab}}$ & $43.0 \pm 34.5^{\mathrm{ab}}$ \\
\hline 1 ppm spinosad & $1.3 \pm 1.1^{a}$ & $2.8 \pm 2.3^{b}$ & $2.0 \pm 1.6^{a b}$ & $0.0 \pm 0.0^{a}$ \\
\hline 5 ppm spinosad & $0.0 \pm 0.0^{b}$ & $0.0 \pm 0.0^{b}$ & $1.0 \pm 0.4^{b}$ & $0.0 \pm 0.0^{a}$ \\
\hline Temephos & $0.0 \pm 0.0^{b}$ & $5.9 \pm 2.8^{\mathrm{ab}}$ & $4.9 \pm 1.3^{a b}$ & $159.0 \pm 67.7^{b}$ \\
\hline
\end{tabular}

Mean values were pooled across the 12 week period following insecticide treatment.

Values followed by identical letters do not differ significantly for comparisons between treatments within each column (Tukey test, $\mathrm{P}>0.05$ ).

Dry season treatment effect, MANOVA, Pillai's trace $0.3705, \mathrm{~F}_{8,88}=2.501$, $P=0.017$.

Wet season treatment effect, MANOVA, Pillai's trace $0.52934, F_{8,88}=3.959$, $P<0.001$.

Non-target organisms were markedly more abundant in the wet season compared to the dry season, with a total of 3129 specimens registered in post-treatment sampling in the wet season. The total number of predatory $T x$. theobaldi was 233 and a total of 2550 ostracods were registered. There were also increased numbers of copeopods $(\mathrm{N}=363)$ compared to the dry season, but few coleopterans $(\mathrm{N}=4)$ and few other insects $(\mathrm{N}=9)$.

Treatment differences in $T x$. theobaldi and ostracod numbers were highly significant in the wet season (Pillai's $\left.F_{8}, \quad 88=3.959, \quad P<0.0001\right)$. Mean numbers of $T x$. theobaldi were lowest in the $5 \mathrm{ppm}$ spinosad treatment and were similar to the control in the other treatments (Table 1). Unexpectedly, mean numbers of ostracods were highest in the temephos and VectoBac treatments for reasons that are not clear, significantly lower in the control treatment and absent in both the spinosad treatments.

\section{Discussion}

Car tires are important habitats for mosquito development because of the high density populations that they can harbor and their frequent proximity to peridomestic and urban settings. In the present study the predominant mosquito species observed developing in car tires were Ae. aegypti, Ae. albopictus, Cx. quinquefasiatus, and $C x$. coronator. Analysis of tire-inhabiting mosquitoes in the eastern United States noted that studies have reported an average of eight species in each mosquito community, including Ae. albopictus among the most commonly reported species in tires in the south-eastern US [4].

The abundance of all the species was seasonally affected; mosquito population densities were approximately twice as high in the wet season compared to the dry season. This difference was particularly marked in Ae. albopictus that represented 53.8\% (eggs on ovitraps) or $37.7 \%$ (laboratory-reared larvae) of the Aedes populations in the dry season compared to $67.9 \%$ or 64.3\% of the Aedes populations during the rainy season, based on insects reared from ovitraps or laboratory-rearing of field-collected larvae, respectively. Similar seasonal differences in the dominance of $A e$. albopictus populations over those of Ae. aegypti have been reported from tire habitats in Brazil [26] and cemetery habitats in Mexico [27].

Spinosad was clearly the most efficient larvicide tested with absolute or near absolute control of developing Aedes spp. and Culex spp. larvae for periods of 68 weeks depending on season and concentration. The $5 \mathrm{ppm}$ spinosad treatment provided complete larvicial activity for between one and two weeks longer than the $1 \mathrm{ppm}$ spinosad treatment. The duration of the control period was broadly similar during the wet and dry seasons, although it was not possible to test this formally as experiments were not replicated within seasons. Nonetheless, this observation indicates that the dilution of spinosad by rainfall during the wet season was unlikely to be a significant factor affecting the residual toxicity of this product in experimental tires. Previous studies by us [28] suggest that exposure to sunlight was likely to have been a significant factor affecting the duration of larvicidal activity, given that the half life of spinosad in an aquatic environment has been estimated at $<3$ days when directly exposed to solar ultraviolet radiation [28]. Despite this, spinosad continued to exhibit partial larvicidal activity for several weeks after larvae were first observed to have recolonized treated tires. It is also important to note that the present study is the first to report effective control of $C x$. coronator by spinosad in habitats where this species is common but see [27], although the relative abundance of this species could not be estimated from laboratory-reared samples that were designed to estimate the variation in the Aedes species present in tires. The neotropical $C x$. coronator is now attracting attention as it rapidly invades temperate areas of the southern United States [29].

The period of larvicidal activity was similar between Aedes and Culex mosquitoes, suggesting that both these genera are broadly similar in their susceptibility to this product. Analysis of published studies on laboratorybased concentration-mortality metrics suggested no systematic differences in susceptibility to spinosad according to genus [25]. According to this analysis $C x$. quinquefasciatus and Ae. aegypti were of intermediate susceptibility whereas the susceptibility of Ae. albopictus was reported to differ markedly in different studies.

Spinosad has been found to eliminate or dramatically reduce numbers of immature aquatic stages of $A e$. 
aegypti and Ae. albopictus in cemetery water containers in Mexico [27,28], Ae. aegypti in water jars in Thailand [30], Cx. pipiens in septic tanks in Turkey [31] or $C x$. pusillus, Cx. pipiens and Aedes caspius in flooded fields in Egypt [32], Cx. quinquefasiatus in field microcosms in California [33], or cesspits, street drains, and disused wells in India [34], Cx. pipiens pipiens, $C x$. restuans, and Ae. japonicus in catchbasins in Connecticut [35], Psorophora columbiae in rice plots in Florida [36], and An. stephensi in water tanks in India [37]. Spinosad was also successfully used alone, or in mixtures with an insect growth regulator, for control of insecticide-resistant $A e$. aegypti populations in Martinique [38,39]. From this, it is clear that relatively few field studies have been performed to date using spinosad, even with mosquito species of major public health performance.

The larvicidal performance of VectoBac was relatively poor with one week of complete control of Aedes spp. larvae in each season and no discernible control of Culex spp. The low persistence of this Bti-based product, also reported in previous trials, particularly when exposed to direct sunlight [40-42], underscores the need to employ sustained release formulations of Bti to achieve more than fleeting control of mosquito larvae [43].

Temephos was intermediate in the duration of larvicidal performance between Bti and spinosad. Temephos granules provided absolute control of Aedes spp. for approximately one week longer than that of Culex spp. However, temephos did not provide the long periods of control reported elsewhere [44,45], for reasons that are unclear.

In a recent smaller-scale study [46], the efficacy of a tablet formulation of spinosad (Natular DT, Clarke Mosquito Control Products Inc., Roselle, IL) was tested against that of $1 \%$ temephos granules for control of tiredwelling mosquitoes in northern Mexico on the border with the United States. Spinosad treatment at an estimated rate of $5.25 \mathrm{pm}$ a.i. performed as well as temephos for control of Aedes spp. and Cx. quinquefasiatus during a 98 day fall and winter period when mosquito populations were very low.

Chironomids were highly sensitive to spinosad although the chironomid fauna of Mexico is very poorly described and only four species have been reported from the state of Chiapas (S. Ibáñez, pers. comm.), arguably the most biodiverse Mexican state. Chironomid densities remained low in spinosad treatments, compared to the control or other treatments, for most of the duration of the study. Laboratory assays have demonstrated spinosad toxicity to a chironomid species of agricultural importance [47], and previous trials reported between 7 and 22 weeks of complete control of chironomids in oviposition traps, depending on treatment concentration and season [48]. It was clear that temephos and VectoBac only briefly affected chironomid populations present in tires. These results suggest that spinosad also merits evaluation for the control of biting midges (Ceratopogonidae) given its high toxicity to members of this family.

Ostracods are common inhabitants of tire habitats [6], and together with $T x$. theobaldi, were the most abundant non-target fauna in experimental car tires. These taxa were not affected by VectoBac treatment due to the high specificity of the bacterial endotoxins, but were reduced in the presence of spinosad or temephos residues. Whether this was due to the toxicity characteristics of these insecticides or due to the reduced numbers of potential mosquito and chironomid prey items present in spinosad and temephos treatments is unclear and requires laboratory toxicity studies. In contrast, Toxorhynchites sp. larvae were observed in the control and spinosad-treated tires on about half of the sample dates although a quantitative analysis was not performed [46]. Temephos treatments have been reported to adversely affect crustacean and benthic macroinvertebrate populations [49-52], reflecting the broad spectrum of insecticidal activity of this compound. In line with its selective ecotoxicological profile, spinosad demonstrated no significant toxicity to a range of aquatic insects in laboratory tests, with the exception of plecopteran species [53]. The susceptibility of daphnids to spinosad varies widely [54], although Daphnia pulex was clearly less susceptible to spinosad than to the organophosphate diazinon [55].

\section{Conclusion}

Spinosad treatments provided effective lasting control of Ae. aegypti, Ae. albopictus, $C x$. quinquefasiatus and $C x$. coronator in experimental car tires in an urban setting in southern Mexico, both in the dry season and the rainy season when populations of these mosquitoes increased markedly. In this sense, spinosad outperformed Vecto$\mathrm{Bac}$ and temephos granule treatments that provided brief or intermediate periods of control. Populations of other organisms, notably chironomids, ostracods and the predatory mosquito $T x$. theobaldi were also reduced in spinosad and temephos treatments. The results of this study contribute to a growing literature indicating that spinosad is a highly effective larvicide against mosquitoes in urban areas, where vector control measures are a key component of public health programs.

\section{Additional file}

Additional file 1: Parasites \& Vectors (Supplemental material online).

Abbreviations

ppm: Parts per million; a.i.: Active ingredient. 


\section{Competing interests}

The authors declare that they have no competing interests.

\section{Acknowledgements}

We thank Sergio Ibáñez for information on the chironomid fauna of Chiapas, Jesús Salgado and Maria de los Ángeles Palomeque for access to the experimental site and to Mauricio Casas, Arnoldo Orozco, Alberto Maldonado (deceased), Magne Roblero, José L. Aguilar, Miguel Muñoz, Damacio Rezendiz, Martín Vázquez, and Miguel López for excellent technical assistance.

\section{Financial support}

The study was funded by COCYTECH project number CHIS-2005-C03-011.

\section{Author details}

${ }^{1}$ Centro Regional de Investigación en Salud Pública - INSP, Tapachula, Chiapas, Mexico. ${ }^{2}$ ECOSUR, Tapachula, Chiapas, Mexico. ${ }^{3}$ Instituto de Ecología AC, Xalapa, Veracruz, Mexico.

\section{Authors' contributions}

CFM obtained funding via a competitive proposal. JGB, JM, NC, CFM performed field studies. JM, NC performed laboratory rearing. JV performed the statistical analyses. CFM, JGB, JV, TW designed the study, TW, CFM wrote the manuscript. All authors read and approved the final version of the manuscript.

\section{Author details}

'Centro Regional de Investigación en Salud Pública - INSP, 19 Pte. esq. 4 Ave. Norte, Tapachula, Chiapas 30700, Mexico; ${ }^{2}$ El Colegio de la Frontera Sur (ECOSUR), Aptdo Postal 36, Tapachula, Chiapas 30700, Mexico, ${ }^{3}$ Instituto de Ecología AC (INECOL), Aptdo Postal 63, Xalapa, Veracruz 91070, Mexico.

Received: 3 January 2012 Accepted: 19 May 2012

Published: 19 May 2012

\section{References}

1. Nawrocki SJ, Craig GB Jr: Further extension of the range of the rock pool mosquito, Aedes atropalpus, via tire breeding. J Am Mosq Control Assoc 1989, 5:110-114

2. Hawley WA, Reiter P, Copeland RS, Pumpuni CB, Craig GB Jr: Aedes albopictus in North America: probable introduction in used tires from northern Asia. Science 1987, 236:1114-1116.

3. Reiter P, Sprenger D: The used tire trade: a mechanism for the worldwide dispersal of container breeding mosquitoes. J Am Mosa Control Assoc 1987, 3:494-501.

4. Yee DA: Tires as habitats for mosquitoes: a review of studies within the eastern United States. J Med Entomol 2008, 45:581-593.

5. Haramis LD: Aedes triseriatus, a comparison of density in tree holes vs. discarded tires. Mosq News 1984, 44:485-489.

6. Kling $L$, Juliano SA, Yee DA: Larval mosquito communities in discarded vehicle tires in a forested and unforested site: detritus type, amount and water nutrient differences. J Vector Ecol 2007, 32:207-217.

7. Yee DA, Kneitel JM, Juliano SA: Environmental correlates of abundances of mosquito species and stages in discarded vehicle tires. J Med Entomol 2010, 47:53-62.

8. Pumpuni $\mathrm{CB}$, Walker ED: Population size and survivorship of adult Aedes triseriatus in a scrap tireyard in northern Indiana. J Am Mosa Control Assoc 1989, 5:166-172.

9. Paulson SL, Hawley WA: Effect of body size on the vector competence of field and laboratory populations of Aedes triseriatus for La Crosse virus. Am Mosa Control Assoc 1991, 7:170-175.

10. Hotez PJ, Bottazzi ME, Franco-Paredes C, Ault SK, Periago MR: The neglected tropical diseases of latin america and the caribbean: a review of disease burden and distribution and a roadmap for control and elimination. PLoS Negl Trop Dis 2008, 2:e300.

11. Gubler DJ: The global threat of emergent/re-emergent vector-borne diseases. In Vector Biology, Ecology and Control. Edited by Atkinson PW. Netherlands: Springer; 2010:39-62.
12. Braks M, van der Giessen J, Kretzschmar M, van Pelt W, Scholte EJ, Reusken C, Zeller $\mathrm{H}$, van Bortel W, Sprong H: Towards an integrated approach in surveillance of vector-borne diseases in Europe. Parasit Vectors 2011, 4:192.

13. Shepard DS, Coudeville L, Halasa YA, Zambrano B, Dayan GH: Economic impact of dengue illness in the Americas. Am J Trop Med Hyg 2011, 84:200-207.

14. Ibáñez-Bernal S, Briseño B, Mutebi JP, Argot E, Rodríguez G, MartínezCampos C, Paz R, de la Fuente-San Román P, Tapia-Conyer R, Flisser A: First record in America of Aedes albopictus naturally infected with dengue virus during the 1995 outbreak at Reynosa, Mexico. Med Vet Entomol 1997, 11:305-309.

15. Casas-Martinez M, Torres-Estrada JL: First evidence of Aedes albopictus (Skuse) in southern Chiapas in Mexico. Emerg Infect Dis 2003, 9:606-607.

16. Paupy C, Delatte H, Bagny L, Corbel V, Fontenille D: Aedes albopictus, an arbovirus vector: from the darkness to the light. Microbes Infect 2009, 11:1177-1185.

17. Gratz NG: Critical review of the vector status of Aedes albopictus. Med Vet Entomol 2004, 18:215-227.

18. Lambrechts L, Scott TW, Gubler DJ: Consequences of the expanding global distribution of Aedes albopictus for dengue virus transmission. PLoS Negl Trop Dis 2010, 4:e646.

19. CDC website West Nile virus., [http://www.cdc.gov/ncidod/dvbid/westnile/ mosquitospecies.htm].

20. Heintze C, Velasco Garrido M, Kroeger A: What do community-based dengue control programmes achieve? A systematic review of published evaluations. Trans R Soc Trop Med Hyg 2007, 101:317-325.

21. WHO: Denque: quidelines for diagnosis, treatment, prevention and control. WHO/ HTM/NTD/DEN/2009.1. Geneva, Switzerland: World Health Organization; 2009.

22. Nauen $\mathrm{R}$ : Insecticide resistance in disease vectors of public health importance. Pest Manag Sci 2007, 63:628-633.

23. Lima EP, Paiva MHS, de Araújo AP, da Silva EVG, da Silva UM, de Oliveira LN, Santana AEG, Barbosa CN, de Paiva Neto CC, Goulart MOF, Wilding CS, Ayres CFJ, de Melo Santos MAV: Insecticide resistance in Aedes aegypti populations from Ceará, Brazil. Parasit Vectors 2011, 4:5.

24. WHO: Spinosad DT in drinking-water: use for vector control in drinking-water sources and containers. WHO/HSE/WSH/10.01/12. Geneva, Switzerland: World Health Organization; 2010.

25. Hertlein MB, Mavrotas C, Jousseaume C, Lysandrou M, Thompson GD, Jany W, Richie SA: A review of spinosad as a natural mosquito product for larval mosquito control. J Amer Mosq Contr Assoc 2010, 26:67-87.

26. Alves-Honório N, Cabello PH, Codeço CT, Lourenço-de-Oliveira R: Preliminary data on the performance of Aedes aegypti and Aedes albopictus immatures developing in water-filled tires in Rio de Janeiro. Mem Inst Oswaldo Cruz 2006, 101:225-228.

27. Marina CF, Bond JG, Casas M, Muñoz J, Orozco A, Valle J, Williams T: Spinosad as an effective larvicide for control of Aedes albopictus and Aedes aggypti, vectors of dengue in southern Mexico. Pest Man Sci 2011, 67:114-121.

28. Pérez CM, Marina CF, Bond JG, Rojas JC, Valle J, Williams T: Spinosad, a naturallyderived insecticide, for control of Aedes aegypti: efficacy, persistence and elicited oviposition response. J Med Entomol 2007, 44:631-638.

29. Gray KM, Burkett-Cadena ND, Eubanks MD: Distribution expansion of Culex coronator in Alabama. J Am Mosa Control Assoc 2008, 24:585-587.

30. Thavara U, Tawatsin A, Asavadachanukorn P, Mulla MS: Field evaluation in Thailand of spinosad, a larvicide derived from Saccharopolyspora spinosa (Actinomycetales) against Aedes aegypti (L.) larvae. SE Asian J Trop Med, Public Health 2009, 40:235-242.

31. Cetin H, Yanikoglu A, Cilek JE: Evaluation of the naturally-derived insecticide spinosad against Culex pipiens L. (Diptera: Culicidae) larvae in septic tank water in Antalya, Turkey. J Vect Ecol 2005, 30:151-154.

32. Bahgat IM, El Kady GA, Temerak SA, Lysandrou M: The natural bioinsecticide spinosad and its toxicity to combat some mosquito species in Ismailia Governorate, Egypt. World J Agric Sci 2007, 3:396-400.

33. Jiang $Y$, Mulla MS: Laboratory and field evaluation of spinosad, a biorational natural product, against larvae of Culex mosquitoes. J Am Mosa Control Assoc 2009, 25:456-466.

34. Sadanandane C, Boopathi-Doss PS, Jambulingam P, Zaim M: Efficacy of two formulations of the bioinsecticide spinosad against Culex quinquefasciatus in India. J Am Mosa Control Assoc 2009, 25:66-73.

35. Anderson JF, Ferrandino FJ, Dingman DW, Main AJ, Andreadis TG, Becnel JJ: Control of mosquitoes in catch basins in Connecticut with Bacillus 
thuringiensis israelensis, Bacillus sphaericus, and spinosad. J Am Mosa Control Assoc 2011, 27:45-55.

36. Allen RA, Lewis CN, Meisch MV: Residual efficacy of three spinosad formulations against Psorophora columbiae larvae in small rice plots. $J$ Am Mosa Control Assoc 2010, 26:116-118.

37. Prabhua K, Murugana K, Nareshkumarb A, Badeeswarana S: Larvicidal and pupicidal activity of spinosad against the malarial vector Anopheles stephensi. Asian Pacif J Trop Med 2011, 4:610-613.

38. Darriet F, Marcombe S, Etienne M, Yébakima A, Agnew P, Yp-Tcha MM Corbel V: Field evaluation of pyriproxyfen and spinosad mixture for the control of insecticide resistant Aedes aegypti in Martinique (French West Indies). Parasit Vectors 2010, 3:88.

39. Marcombe S, Darriet F, Agnew P, Etienne M, Yp-Tcha MM, Yébakima A Corbel V: Field efficacy of new larvicide products for control of multiresistant Aedes aegypti populations in Martinique (French West Indies). Am J Trop Med Hyg 2011, 84:118-126.

40. Mulligan FS, Schaefer $\mathrm{CH}$, Wilder WH: Efficacy and persistence of Bacillus sphaericus and B. thuringiensis $\mathrm{H} .14$ against mosquitoes under laboratory and field conditions. J Econ Entomol 1980, 73:684-688.

41. Kramer VL: Efficacy and persistence of Bacillus sphaericus, Bacillus thuringiensis var. israelensis, and methoprene against Culiseta incidens (Diptera: Culicidae) in tires. J Econ Entomol 1990, 83:1280-1285.

42. Batra CP, Mittal PK, Adak T: Control of Aedes aegypti breeding in desert coolers and tires by use of Bacillus thuringiensis var. israelensis formulation. J Amer Mosa Control Assoc 2000, 16:321-323.

43. Lacey LA, Urbina MJ, Heitzman CM: Sustained release formulations of Bacillus sphaericus and Bacillus thuringiensis $(\mathrm{H}-14)$ for control of container breeding Culex quinquefasciatus. Mosa News 1984, 44:26-32.

44. Beehler JW, Quick TC, DeFoliart GR: Residual toxicity of four insecticdes to Aedes triseriatus in scrap tires. J Am Mosa Control Assoc 1991, 7:121-122.

45. Morris CD, Dame DA, Robinson JW: Control of Aedes albopictus in waste tire piles with reduced rates of temephos-treated granules. J Am Mosa Control Assoc 1996, 12:472-476.

46. Garza-Robledo AA, Martínez-Perales JF, Rodríguez-Castro VA, Quiroz-Martínez $\mathrm{H}$ : Effectiveness of spinosad and temephos for the control of mosquito larvae at a tire dump in Allende, Nuevo Leon, Mexico. J Am Mosq Control Assoc 2011, 27:404-407.

47. Stevens MM, Helliwell S, Hughes PA: Toxicity of Bacillus thuringiensis var. israelensis formulations, spinosad, and selected synthetic insecticides to Chironomus tepperi larvae. J Am Mosa Control Assoc 2005, 21:446-450.

48. Bond JG, Marina CF, Williams T: The naturally-derived insecticide spinosad is highly toxic to Aedes and Anopheles mosquito larvae. Med Vet Entomol 2004, 18:50-56.

49. Yap HH, Lau BL, Leong YP: Laboratory and field tests of temephos (Abate) on mosquito larvae and non-target organisms in rice fields in Malaysia. SE Asian J Trop Med Public Health 1982, 13:646-653.

50. Fortin C, Marie A, Leclair R: The residual effect of temephos (Abate 4-E) on nontarget communities. J Am Mosa Control Assoc 1987, 3:282-288.

51. Brown MD, Watson TM, Green S, Greenwood JG, Purdie D, Kay BH: Toxicity of insecticides for control of freshwater Culex annulirostris (Diptera: Culicidae) to the nontarget shrimp, Caradina indistincta (Decapoda: Atyidae). J Econ Entomol 2000, 93:667-672.

52. Leveque $C$ : The use of insecticides in the onchocerciasis control programme and aquatic monitoring in West Africa. In Ecotoxicology and Climate. Edited by Bordeau P, Haines JA, Klein W, Krishna Murti CR. Chichester, UK: Wiley; 1989:317-335.

53. Infante-Rodríquez DA, Novelo-Gutiérrez R, Mercado G, Williams T: Spinosad toxicity to Simulium spp. larvae and associated aquatic biota in a coffee-growing region of Veracruz State, Mexico. J Med Entomol 2011, 48:570-576

54. Deardorff AD, Stark JD: Acute toxicity and hazard assessment of spinosad and R-11 to three cladoceran species and Coho salmon. Bull Environ Contam Toxicol 2009, 82:549-553.

55. Stark JD, Vargas RI: Demographic changes in Daphnia pulex (Leydig) after exposure to the insecticides spinosad and diazinon. Ecotoxicol Environ Safety 2003, 56:334-338.

doi:10.1186/1756-3305-5-95

Cite this article as: Marina et al: Spinosad: a biorational mosquito larvicide for use in car tires in southern Mexico. Parasites \& Vectors 2012 5:95.

\section{Submit your next manuscript to BioMed Central and take full advantage of:}

- Convenient online submission

- Thorough peer review

- No space constraints or color figure charges

- Immediate publication on acceptance

- Inclusion in PubMed, CAS, Scopus and Google Scholar

- Research which is freely available for redistribution 